\title{
Some considerations in using the small punch testing for thermally sprayed CoNiCrAIY coatings
}

\author{
H. Chen ${ }^{\mathrm{a}, *}$, A. Rushworth ${ }^{\mathrm{a}}$, W. Sun ${ }^{\mathrm{b}}$, J. He ${ }^{\mathrm{c}}$ and H. Guo ${ }^{\mathrm{c}, *}$ \\ ${ }^{a}$ Department of Mechanical, Materials and Manufacturing Engineering, Faculty of \\ Science and Engineering, University of Nottingham Ningbo China, Ningbo 315100, \\ China \\ ${ }^{b}$ Department of Mechanical, Materials and Manufacturing Engineering, Faculty of \\ Engineering, University of Nottingham, Nottingham NG7 2RD, UK

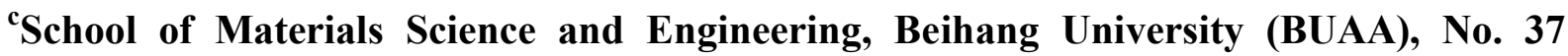 \\ Xueyuan Road, Beijing 100191, China
}

\begin{abstract}
Small punch testing exhibits great potential in mechanical characterisation of thin coatings. This testing method can be used to determine the mechanical performance of thermally sprayed coatings, especially to qualitatively characterise the effects of coating defects on the mechanical behaviour. In this work, some considerations in using the small punch testing for coatings are presented through a microstructure evolution analysis of a vacuum plasma sprayed CoNiCrAlY coating under small punch test. The CoNiCrAlY coating was characterised with a large number of un-melted particles as the coating defects. It is shown that the clamping in the small punch test rig can result in micro-cracking around the unmelted particles in the coating prior to testing. It is also found that the un-melted particles in the coating act as predominant cracking sites and fast failure occurred around the un-melted particles. Careful considerations need to be taken into account when using the small punch test for coatings to avoid any changes in the coating microstructure and plasticity during the clamping stage.
\end{abstract}


Keywords: Small punch test; Mechanical behaviour; CoNiCrAlY coatings; Un-melted particles; Cracking

*Corresponding Authors.

E-mail address: Hao.Chen@nottingham.edu.cn, guo.hongbo@buaa.edu.cn 


\section{Introduction}

Since the first introduction of the small punch testing (SPT) technique in 1980s, this small specimen test method has been widely used to mechanically characterise the power plant steels, weldments and alloys [1-11]. A CEN Code of Practice was established to specify the geometrical set-up and test procedures of SPT [12]. Among the available small specimen test methods, the unique characteristic of the SPT is the disc-type specimen $(8-10 \mathrm{~mm}$ in diameter, 0.25-0.5 $\mathrm{mm}$ in thickness), which allows the life assessment to be achieved from a small volume of materials. In recent decades, SPT has been developed into two categories, namely the small punch tensile test to investigate the fracture behaviour and the small punch creep test to examine the creep characteristics $[13,14]$. Works concerned on the SPT for mechanical performance evaluation of various materials have been extensively reported, ranging from experimental studies to numerical simulations [15-24]. However, due to the complexity of biaxial loading in SPT, the data interpretation remains challenging and no universally accepted methodology has been developed yet. Nevertheless, SPT has been demonstrated to be a useful tool for mechanical characterisation of materials, even without the fully verified route for data interpretation [25].

More recently, the application of SPT has been expanded to other areas where the availability of materials is limited, such as coatings [26]. In general, coatings exhibit unique mechanical and chemical properties when comparing to the bulk materials. It has been increasingly difficult to characterise the mechanical performance of coatings by conventional uniaxial testing due to the small coating thickness and the delamination between the coating and substrate [27]. The SPT appears to have the potential to evaluate the mechanical behaviour of coatings since it has the capability in testing disc specimens with thicknesses close to typical coating thicknesses $(\sim 0.5 \mathrm{~mm})$. Kameda et al. used the SPT to evaluate the high temperature mechanical degradation of CoCrAlY coatings [28-30]. Eskner et al. employed the SPT to investigate the temperature dependent mechanical properties of $\mathrm{NiCoCrAlY}$ and $\mathrm{NiAl}$ 
coatings [31, 32]. Soltysiak et al. reported a study on using SPT to characterise a thermally sprayed IN625 coating [33]. Chen et al. applied SPT to evaluate the ductile-to-brittle transition and creep behaviour of CoNiCrAlY coatings [34-36]. These are the limited studies available on using the SPT for coatings, which have demonstrated the importance and suitability of using the SPT for mechanical characterisation of thermally sprayed coatings.

However, further considerations need to be taken into account when using the SPT for coatings. Coatings are usually obtained by spray deposition methods, such as high velocity oxy-fuel (HVOF) thermal spray or vacuum plasma spray (VPS) [37, 38]. Depending on the spray parameters, the splat-on-splat nature of thermally sprayed coatings can result in various defects, i.e. pores, oxide inclusions and un-melted particles $[39,40]$. This means the coatings generally exhibit quite different structures and properties than the cast alloys of the same chemistry $[41,42]$. The defects embedded in the coatings can have a significant influence on their mechanical response during the SPT. Therefore, in this paper, the performance of a thermally sprayed CoNiCrAlY coating with some initial defects is assessed via SPT under constant load (small punch creep test). The CoNiCrAlY coating is deliberately prepared with a number of un-melted particles using vacuum plasma spray. The microstructure evolution of this CoNiCrAlY coating during SPT is investigated to identify the roles of un-melted particles on the mechanical response of this CoNiCrAlY coating in the SPT. Some general comments and considerations for future exploitation of the SPT on thermally sprayed coatings are also addressed.

\section{Materials and Methods}

The CoNiCrAlY coating was prepared by vacuum plasma spraying using a commercially available Amdry 9951 powder with a nominal composition Co-31.7\%Ni-20.8\%Cr-8.0\%Al$0.4 \% \mathrm{Y}$ (all in $\mathrm{wt} \%$ ). The size range of the powder particles is $5-38 \mu \mathrm{m}$, as characterised by a laser diffractometer. The detailed spray parameters and processes are given elsewhere [40]. 
Free-standing CoNiCrAlY coating alloys with an approximate thickness of $0.5 \mathrm{~mm}$ were obtained by debonding the coating from substrate. The as-sprayed coatings were subjected to an initial heat treatment of $2 \mathrm{~h}$ at $1100{ }^{\circ} \mathrm{C}$ to fully develop the microstructure and reduce the existing coating porosity. Disc specimens of $8 \mathrm{~mm}$ in diameter were cut from the heat treated coatings by wire electro-discharge machining and were carefully ground and polished to a final thickness of approximately $430 \mu \mathrm{m}$ to minimise the effects of rough coating surface on the subsequent small punch testing.

Tests were carried out in the E.ON test rig at $750{ }^{\circ} \mathrm{C}$ in air with a load range of 50-100 N. The configuration of the rig set-up is illustrated in Fig. 1. The small punch test rig consists of a rig frame (A), a loading pan (B), a linear variable differential transformer (LVDT) transducer (C), a transmitting rod (D), a furnace $(\mathrm{E})$, a hemispherical punch $(\mathrm{F})$, a stopper $(\mathrm{G})$, an aligning bush $(\mathrm{H})$, an upper die $(\mathrm{I})$, a lower die $(\mathrm{J})$, a tube $(\mathrm{K})$ and a clamping nut $(\mathrm{L})$. The specimens were clamped between the upper and lower die under a clamping torque of $\sim 40 \mathrm{Nm}$ as measured by a "Britool" torque wrench. Prior to loading, the coating specimens were heated to the target test temperature and stabilised for $5 \mathrm{~h}$ to remove the residual stress and work hardening from the specimen preparation process. The microstructure of the coating specimens before and after testing was investigated via a FEI XL30 scanning electron microscope (SEM) using secondary electron and backscatter electron imaging. The electron backscattered diffraction (EBSD) was employed to elucidate the cracking mechanism in the deformed sample prior to failure. 


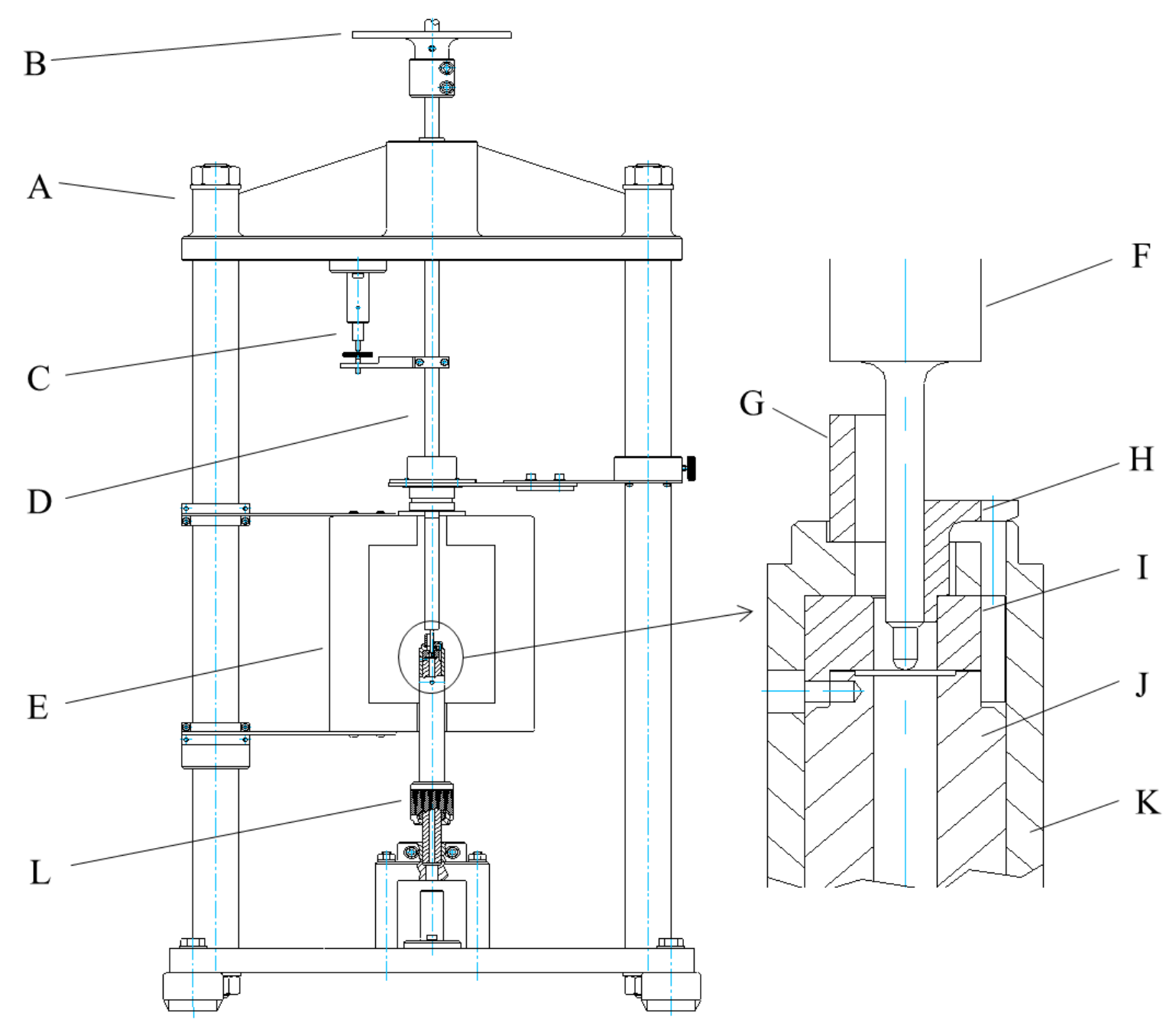

Fig. 1. A schematic diagram of the small punch test rig set-up.

\section{Results}

\subsection{Microstructure of coatings prior to testing}

The microstructure of the initially heat-treated CoNiCrAlY coatings is shown in Fig. 2. The coating exhibits a clear two phase structure, consisting of the dark contrast $\beta$-NiAl phase and the bright contrast $\gamma$-Ni phase. The volume fraction of the $\beta$ phase is measured to be around $30 \%$ by image analysis. The coating shows an oxide-free structure, which agrees well with the nature of vacuum plasma spraying in limiting the oxidation of in-flight powder particles [43]. It is seen from Fig. 2a that the heat treated CoNiCrAlY coating exhibits very little porosity, showing a dense microstructure of the coating. Some spherical features are further noticed in Fig. $2 b$ and they are presumably the un-melted particles which retain their original shape 
during the spraying process. Fig. 3 depicts the morphology of the coating surface. The unmelted particles are spherical in morphology and undergo limited plastic deformation, which is consistent with the cross-sectional microstructure of the coating in Fig. $2 \mathrm{~b}$.
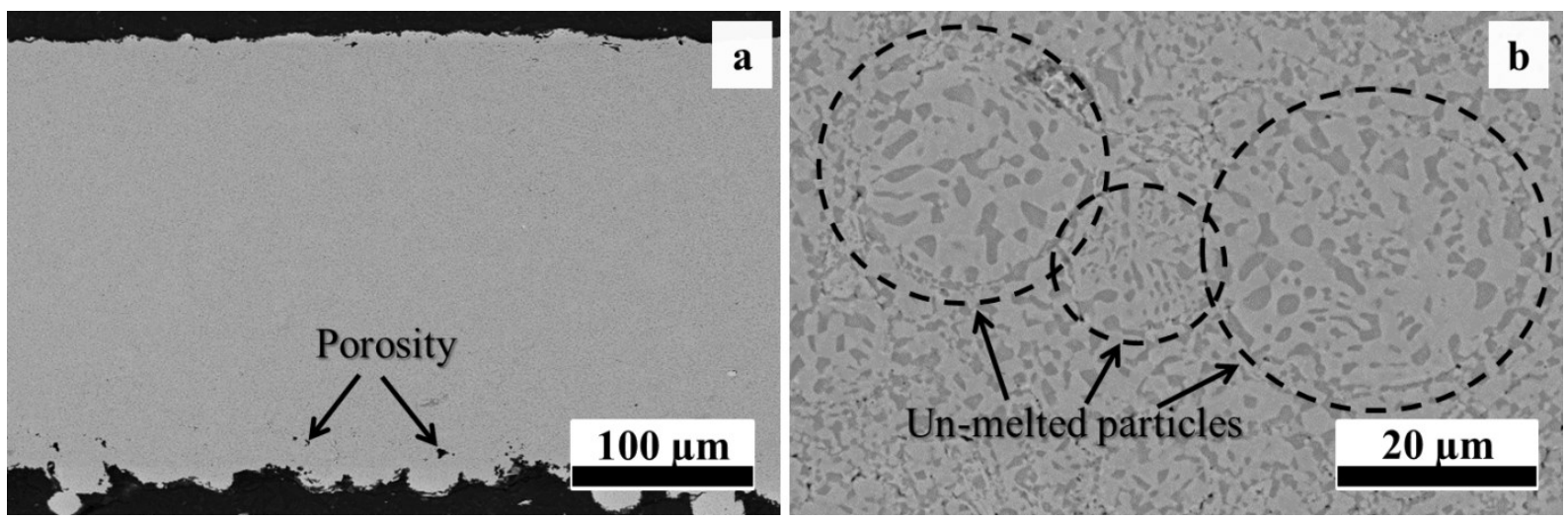

Fig. 2. Microstructure of the heat treated VPS CoNiCrAlY coating at $1100{ }^{\circ} \mathrm{C}$ for $2 \mathrm{~h}$ : (a) the low magnification image showing the oxide-free and pore-free structure; (b) the high magnification image show the two phase structure with un-melted particles highlighted.

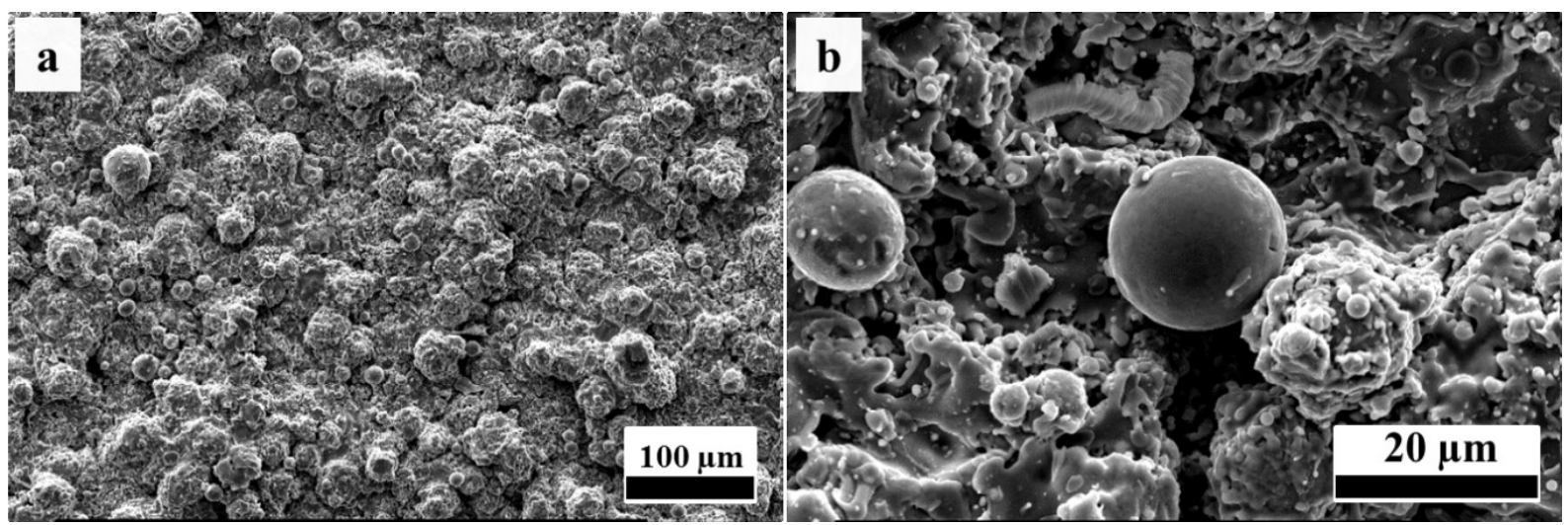

Fig. 3. The morphology of the CoNiCrAlY coating surface: (a) the low magnification image showing the large number of un-melted particles; (b) the high magnification image showing the spherical shapes of un-melted particles.

Prior to testing, the coating specimens were clamped in the test rig at room temperature with a clamping torque of $40 \mathrm{Nm}$ (equivalent clamping stress $\sim 250 \mathrm{MPa}$ ). This clamping torque was chosen based on the previous studies to prevent the sample slipping during the test $[34,35]$. Since the un-melted particles can behave differently compared to the adjacent regions in the 
coating, the specimens after clamping were taken out from the rig to identify if any microstructural discrepancy occurred. Fig. 4 shows the microstructure of coating specimen from the clamped region. Some dark contrast features are found in Fig. 4a and these are the micro-cracks seen in Fig. 4b. The micro-cracks are mainly developed around the un-melted particles, indicating that the boundaries of the un-melted particles are likely to act as crack initiation sites. No cracks are found in the unclamped regions of the specimen. It is evident that the initial coating exhibits a crack-free structure, as seen in Fig. 2. Thus, it is believed the micro-cracks seen in Fig. 4 are largely resulted from the clamping stage in the test rig. The initial cracking of the coating specimen can significantly affect the initial plasticity of the material prior to SPT. Though careful considerations have been thought to reduce the clamping force, it is essential to maintain sufficient specimen clamping to prevent the slipping of the specimen in the subsequent SPT.

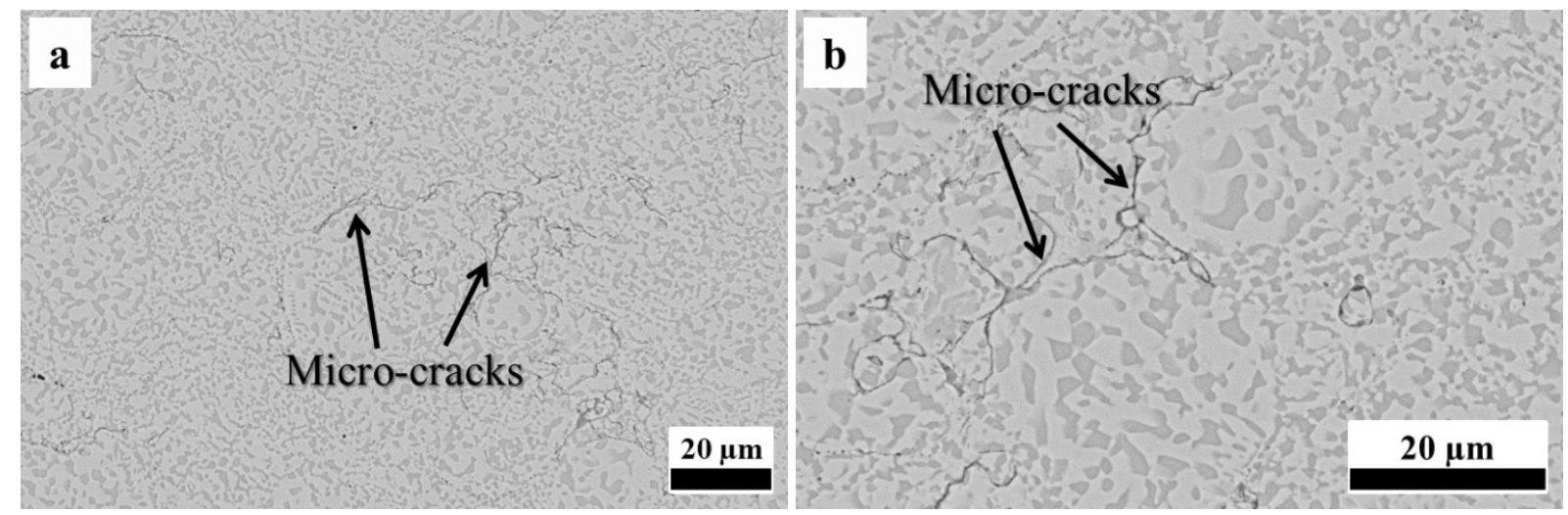

Fig. 4. The microstructure of the VPS CoNiCrAlY coating in the clamped region prior to testing: (a) the low magnification image showing some dark contrast features; (b) the high magnification image showing micro-cracks along the un-melted particles.

\subsection{Small punch creep test results}

The SPT results under various constant loads at $750{ }^{\circ} \mathrm{C}$ are shown in Fig. 5. It can be seen the coatings fail quite rapidly at loads between $94.4-100 \mathrm{~N}$. The test curves reflect the large and instant plastic deformation upon loading in this load range. At lower loads between $75-81.5 \mathrm{~N}$, the results exhibit the typical creep displacement curves in SPT, with an initial primary region, 
a steady-state secondary region and a tertiary region leading to fracture. The displacement rate in the secondary region decreases with the load. It should be noted that the total failure times at this load range are still quite small, varying between 4.5-14.5 h. Given the short period of the failure times, it is believed this CoNiCrAlY coating material mainly undergoes plastic deformation rather than creep. Previous work has demonstrated that the time to failure of this crack-free CoNiCrAlY coating varies from $20-400 \mathrm{~h}$ at a similar load range [34]. Since the clamping torque used is the same and the major difference is the amount of un-melted particles, it is indicated that the un-melted particles and the initial cracking can significantly influence the time to failure of this CoNiCrAlY coating during the SPT.

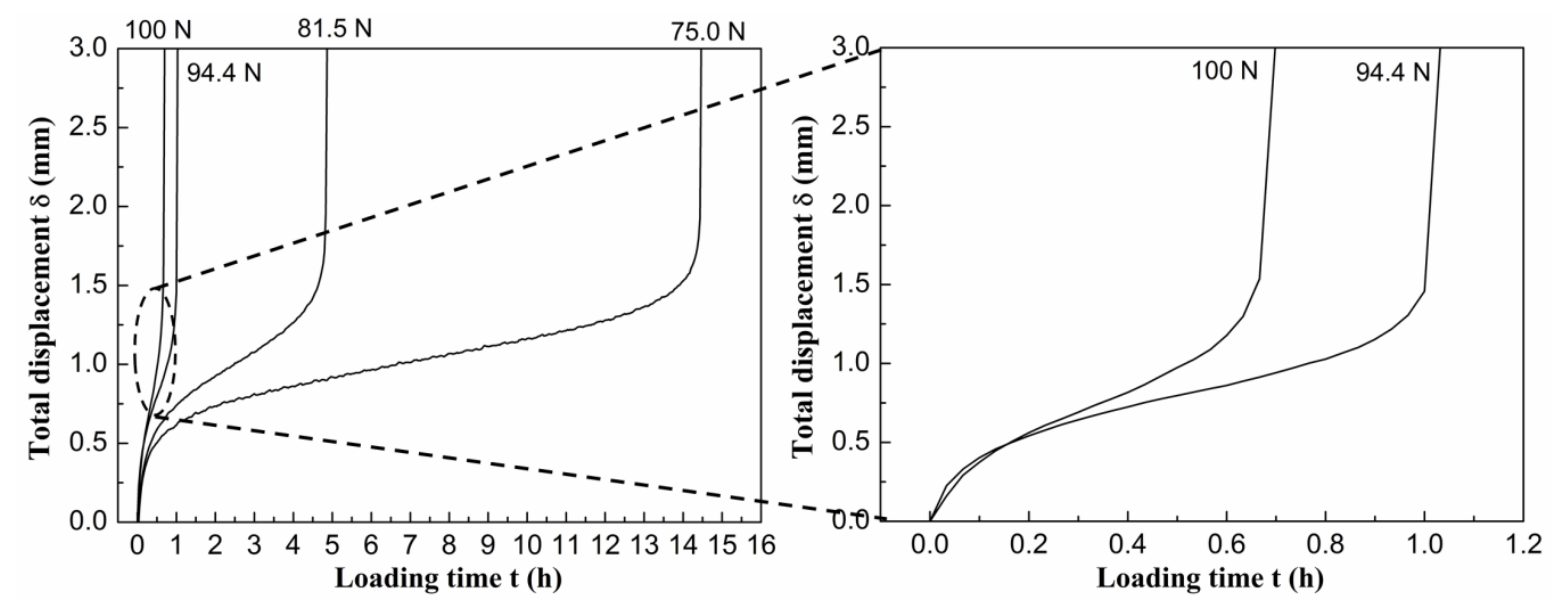

Fig. 5. The SPT results for VPS CoNiCrAlY coating at $750{ }^{\circ} \mathrm{C}$ under a load range of $75-100$ $\mathrm{N}$.

\subsection{Post-test microstructural analysis}

Fig. 6 shows the fracture surfaces of the CoNiCrAlY coating after SPT. The domed shape of the failed specimen is seen in Fig. 6a, indicating the deformation of the specimen during the test. The rough fracture surface indicates that extensive tearing has occurred. This is indeed seen in Fig. 6b. It has been reported that the ductile-to-brittle transition of this CoNiCrAlY coating alloy is between $500-700{ }^{\circ} \mathrm{C}[35,44]$. The SPTs conducted in this study are at $750{ }^{\circ} \mathrm{C}$, which falls into the ductile region of this material. As a result, the fracture surface exhibits the tearing behaviour. Since there are a large number of un-melted particles in the coating, the 
evidence of un-melted particles on the fracture surface can also be found, as shown in Fig. 6c.

The limited bonding between the un-melted particles and the bulk material is seen from Fig. $6 \mathrm{c}$, which is likely resulted from the initial cracking around the un-melted particles.
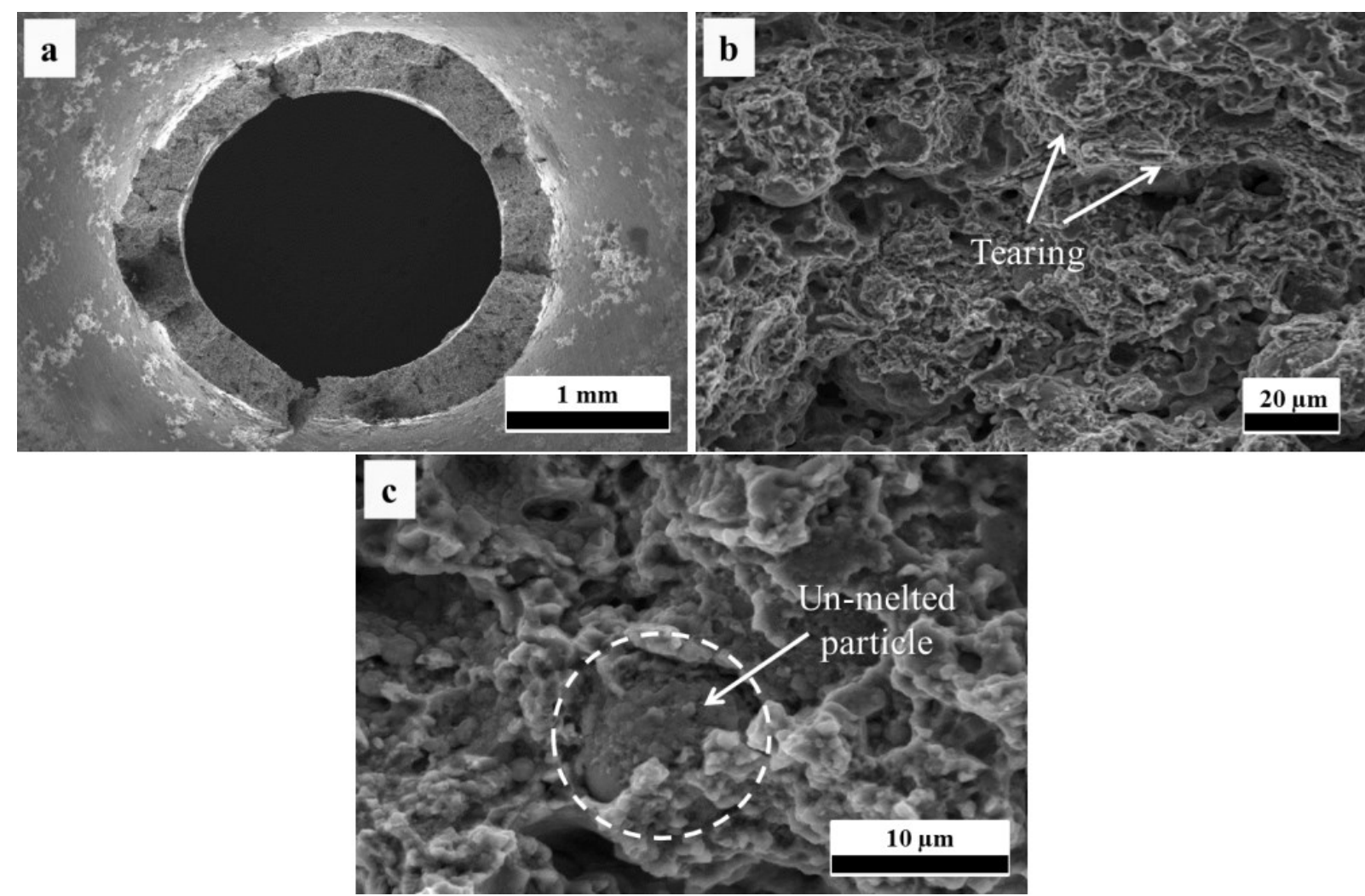

Fig. 6. The fracture surface of the VPS CoNiCrAlY coating after the SPT at $75 \mathrm{~N}$ : (a) the dome-shaped fracture surface; (b) the evidence of tearing; (c) un-melted particle at the fracture surface.

The cross-sectional microstructure of the deformed specimen for $1000 \mathrm{~h}$ at $50 \mathrm{~N}$ prior to failure is elucidated in Fig. 7. The deformed shape of the specimen agrees well with the dome-shaped specimen since the failure generally occurs at the edge of contact between the punch and specimen. The dark contrast macroscopic cavities are seen throughout the coating specimen in Fig. 7a. The evidence of cracking around un-melted particles is still visible in Fig. 7b. It is found that the initial micro-cracks have grown and propagated during the SPT. In comparison to the microstructure of the clamped specimen in Fig. 4, it is seen that the void nucleation also occurred during the deformation in SPT. Such voids tend to link together to 
form large cavities, as seen in Fig. 7b. The continuous linkage of large cavities and the propagation of the initial micro-cracks eventually lead to the failure of the coating specimen in SPT.
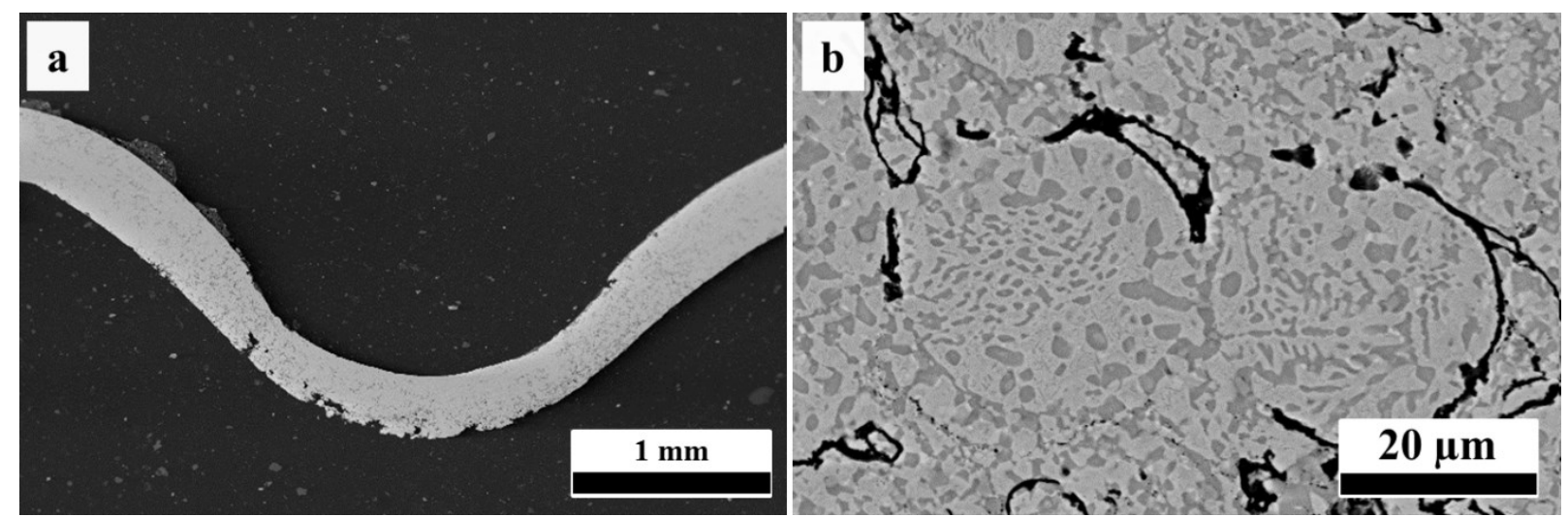

Fig. 7. The cross-sectional microstructure of the deformed CoNiCrAlY coating but without final failure at $750{ }^{\circ} \mathrm{C}$ for $1000 \mathrm{~h}$ under a load of $50 \mathrm{~N}$ : (a) low magnification image show the shape of the deformed coating; (b) high magnification image showing the linkage of macrocracks and cavities.

Fig. 8 shows an EBSD inverse pole figure and a phase map of the cracking around the unmelted particles in the deformed sample from Fig. 7. The highlighted area is the un-melted particle and it can be seen that the initial micro-cracks around the un-melted particle have grown significantly to form large cavities in the coating. It is also evident that the cracks and cavities are also along the grain boundaries, showing an intergranular cracking behaviour of this CoNiCrAlY coating material at $750{ }^{\circ} \mathrm{C}$. The evolution from initial micro-cracks to the large macro-cracks and cavities are likely resulted from the stretching effects from the SPT. It is noticed that the primary deformation upon loading is quite large in Fig. 5. This large instant deformation causes the opening of the micro-cracks. As the sample continues to deform, the micro-cracks grow further to become macro-cracks. Some voids that are close to the unmelted particle are also found to exist, which agrees well with Fig. 7b. This gives further evidence that the failure mechanism is likely to be the linkage of large cavities and voids. 

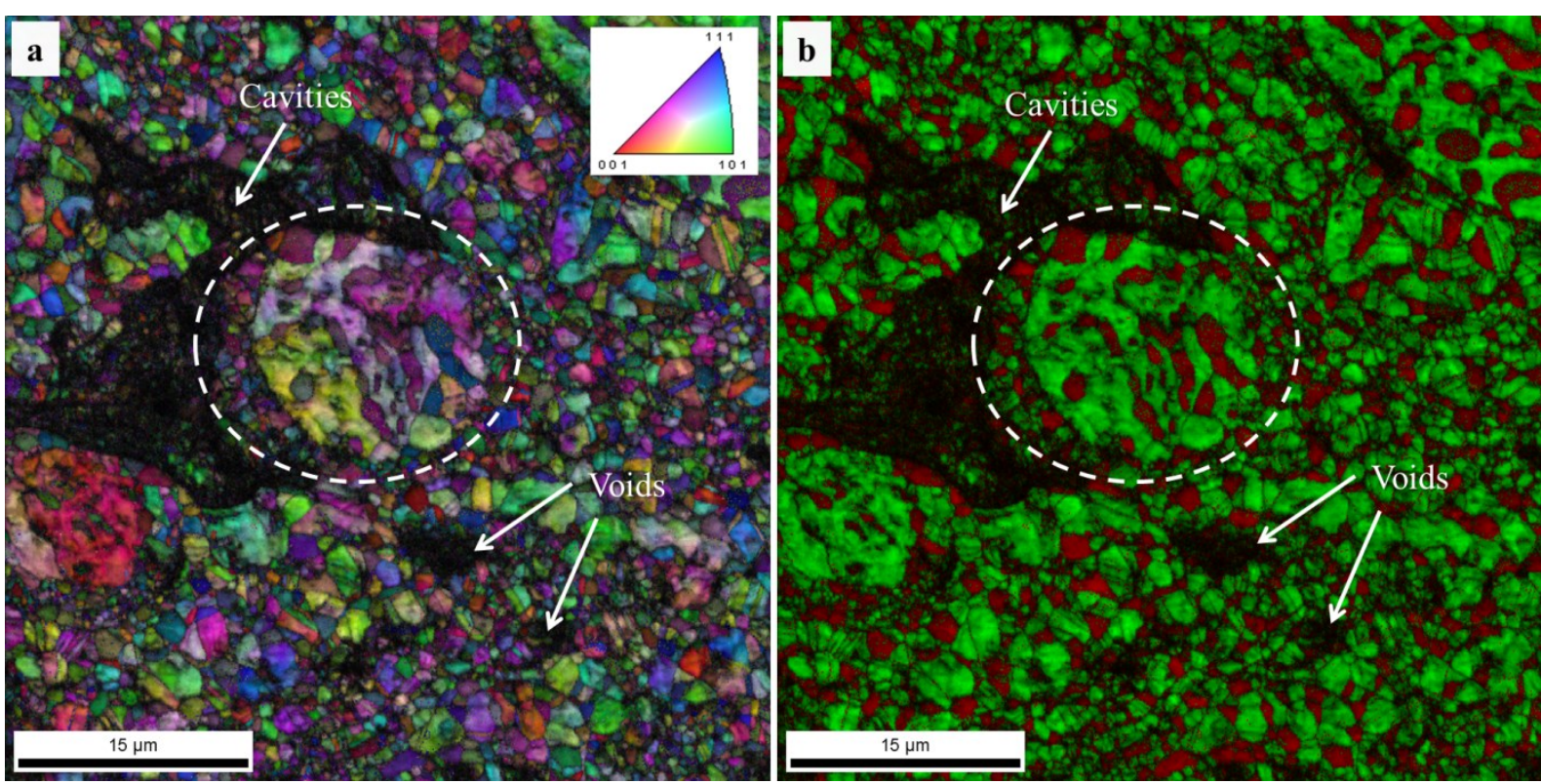

Fig. 8. The EBSD inverse pole figure (a) and phase map (b) of the large cavities around the un-melted particle in the long term deformed sample but prior to failure.

An EBSD mapping of a region close to the edge of contact between the punch and specimen is shown in Fig. 9. Since the edge of contact is usually the failure sites of SPT samples, extensive voids and cavities are seen from Fig. 9. The spherical feature in Fig. 9 is believed to be the un-melted particle. The cavities mainly developed along the particle boundary and the evolution of such cavities limits the integrity of the coating. The further propagation of these cavities leads to the fracture of the sample. This is supported by the evidence that very little material exists across the cavities and the effective bonding in the coating diminishes. 


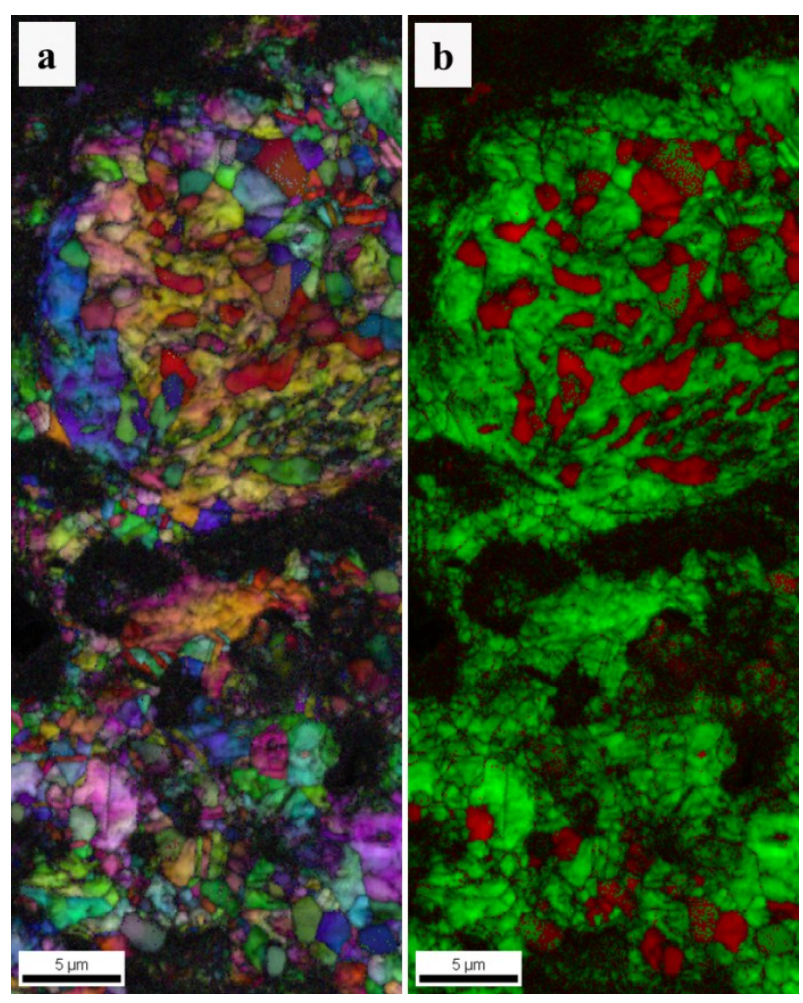

Fig. 9. The EBSD inverse pole figure (a) and phase map (b) of the region close to the edge of contact between the punch and specimen.

\section{Discussion}

The un-melted particles are the common defects in the thermally sprayed coatings when inappropriate spray parameters are used. The interactions between powder feed rate, spray energy, gas flow rate and stand-off distance are the dominating factors in the un-melted particle density. Unlike the high velocity oxy-fuel (HVOF) thermal spray where the particle velocity is usually high $(300-800 \mathrm{~m} / \mathrm{s})$, the impact velocity of particles in the vacuum plasma spraying (VPS) is much smaller, which means the particle bonding mechanism is different [45]. The bonding of particles in VPS is mainly achieved by solidifications of molten particles rather than the deformation of particles. As seen in Fig. 2\&3, the un-melted particles in VPS exhibit spherical shapes with limited bonding. The limited deformation of the un-melted particles indicates the less work hardening effects in the coating, and as a consequence, smaller mechanical strengthening is obtained when comparing to the HVOF coatings. 
Previously reported work showed that no initial cracking occurred in the HVOF CoNiCrAlY coatings during SPT [34], which further supports this view.

Compressive stresses were imposed on coating upon clamping by the upper and lower die in the small punch test rig. It is found from Fig. 4 that the un-melted particles retain their original spherical shape with little deformation after clamping, indicating that the particles have sufficient strength to withstand the compressive stresses. This is indeed supported by the evidence that the cracking mostly occurs around the un-melted particles but not within the particles. Since the bonding strength is limited at the particle boundaries, the deformability of the un-melted particles and their adjacent coating materials is likely to be different. This allows the localised shearing to occur in the coating, especially at the particle boundaries during clamping. But the limited bonding of the un-melted particles can decrease the shearing strength at the particle boundaries. As a result, cracking is likely to occur around the unmelted particles, as indeed seen in Fig. 4.

Due to the initial cracking and the associated changes in the plasticity of the coating material, the SPT results can only reflect the mechanical response of the cracked sample. This means the derivation of the mechanical properties becomes less practical in this study. As discussed previously, the coatings have undergone an initial cracking stage prior to the SPT. The initial cracks which act as large defects have already changed the load-carrying capacity of the coating material. During the SPT, localised stretching occurs as the specimen deforms, whilst the resistance to the cavity nucleation depends on the bonding strength of the splats. The presence of micro-cracks in the coating, however, limits the effective bonding of the splats and weakens the mechanical strength of the coatings. Thus the initial micro-cracks act as fast fracture sites of the coating and short failure times are resulted in the SPT for this VPS CoNiCrAlY coating with a large number of un-melted particles in Fig. 5.

Although the rapid failure occurs in this VPS CoNiCrAlY coating, the characteristics of the fracture surface in Fig. 6 are in good consistency with other small punch creep studies [34, 
46]. The unique feature of the fracture surface in this work is the evidence of un-melted particles. This agrees well with initial microstructure of the coating, in which a large number of un-melted particles was produced in the coating. The opening of the micro-cracks around the un-melted particles during SPT results in the formation of macro-cracks and large cavities, as seen in Fig. 7. Since the voids nucleation is seen in Fig. 8, it is believed that the voids also tend to link together to form large cavities. The integrity of the coating is thus significantly affected by the cavities, especially at the regions close to the edge of contact from Fig. 9. The growth and propagation of the cavities around the un-melted particles eventually lead to the failure of the coating specimen.

To cope with the initial cracking around the un-melted particles in this VPS CoNiCrAlY coating, some considerations are proposed here to minimise these issues during SPT. It is known that the bcc $\beta$-NiAl phase in this CoNiCrAlY coating, as seen in Fig. 2b, exhibits a ductile-to-brittle transition behaviour $[47,48]$. Since the volume fraction of the $\beta$ phase is around $30 \%$, the CoNiCrAlY coating also exhibits a ductile-to-brittle transition behaviour. It has been reported from previous studies that the DBTT of this CoNiCrAlY coating is between $500-700{ }^{\circ} \mathrm{C}[26,35]$. Thus to minimise the tendency of coating cracking during clamping at room temperature, it is proposed here that clamping at temperatures above DBTT can be an option to avoid the initial cracking. In our normal test procedure, we clamp the sample at room temperature and then align the punch axis to the centre of the specimen, followed by a heating stage to the test temperature prior to testing. Due to this experimental procedure and the limitation of our rig set-up, clamping at high temperature has not been achieved yet. Another aspect to consider is identifying the appropriate clamping torque. In this study, we used the same clamping torque from our previous testing on HVOF CoNiCrAlYcoatings [34]. This clamping torque $(\sim 40 \mathrm{Nm})$ is also based on our past experience in small punch creep testing of P91 steels [9]. But since the un-melted particles in this VPS CoNiCrAlY can well affect the mechanical integrity of the coating, appropriate clamping force may need to be 
considered to avoid the initial cracking around the un-melted particles and to allow sufficient clamping of the specimen. It is also noticed that new cracks and voids are also developed during the testing process from Fig. 7 and Fig. 8. Thus it is believed that the fast cracking and rapid failure may still occur even without initial cracking in the sample, due to the large number of un-melted particles in the coating.

\section{Concluding remarks}

The small punch test technique, due to its suitability to test thin specimens, can be used to test the mechanical performance of thermally sprayed CoNiCrAlY coatings. But thermally sprayed coatings usually exhibit many defects, i.e. un-melted particles, which results in mechanical discrepancies within the coating. When such coatings with un-melted particles are subjected to SPT, initial cracking is likely to occur around the un-melted particles during the clamping stage of SPT, due to the limited bonding between the un-melted particles and the bulk coating materials. The initial cracking can significantly affect the mechanical response of the CoNiCrAlY coating material in the subsequent SPT. Although the SPT results of such pre-cracked coatings are superficially similar to the conventional SPT curves in power plant steels, the rapid time to failure is obtained due to the initial micro-cracks. The test results can only reflect the mechanical behaviour of the cracked coatings. Therefore, careful considerations need to be taken into account when using the SPT for mechanical characterisation of such thermally sprayed coating since the initial plasticity of the coating has been changed in the clamping stage, especially when cracking has occurred due to the defects in the coating. Appropriate clamping force must be considered when testing thermally sprayed coatings to avoid the large changes in the coating plasticity. And clamping at high temperatures can also be considered to avoid the initial cracking of the coating materials.

\section{Acknowledgments}


The authors would like to thank Prof. Thomas Hyde, Prof. Graham McCartney and Prof. John

Nicholls for helpful discussions. The authors would like to acknowledge Faculty of Engineering, University of Nottingham for provision of laboratory facilities. This research was supported by Zhejiang Provincial Natural Science Foundation of China under Grant No. LQ18E010002, Ningbo Natural Science Foundation under Grant No. 2018A610168 and Qianjiang Talent Scheme under Grant No. QJD1803012.

\section{References}

[1] M.P. Manahan, A new postirradiation mechanical behavior test-the miniaturized disk bend test, Nucl. Technol. 63 (1983) 295-315.

[2] M.P. Manahan, A.S. Argon, O.K. Harling, The development of a miniaturized disk bend test for the determination of postirradiation mechanical-properties, J. Nucl. Mater. 103 (1982) 1545-1550.

[3] X. Mao, T. Shoji, H. Takahashi, Characterization of fracture behaviour in small punch test by combined recrystallization-etch method and rigid plastic analysis, J. Test. Eval. 15 (1987) 30-37.

[4] J.H. Bulloch, A review of the ESB small punch test data on various plant components with special emphasis on fractographic details, Eng. Failure Anal. 9 (2002) 511-534.

[5] T.H. Hyde, W. Sun, J.A. Williams, Requirements for and use of miniature test specimens to provide mechanical and creep properties of materials: a review, Int. Mater. Rev. 52 (2007) 213-255.

[6] F. Dobes, K. Milicka, Application of creep small punch testing in assessment of creep lifetime, Mater. Sci. Eng. A 510 (2009) 440-443.

[7] Y.W. Ma, S. Shim, K.B. Yoon, Assessment of power law creep constants of Gr91 steel using small punch creep tests, Fatigue Fract. Eng. Mater. Struct. 32 (2009) 951-960.

[8] F. Dobeš, K. Milička, Estimation of ductility of Fe-Al alloys by means of small punch test, Intermetallics 18 (2010) 1357-1359.

[9] T.H. Hyde, M. Stoyanov, W. Sun, C.J. Hyde, On the interpretation of results from small punch creep tests, J. Strain Anal. Eng. Des. 45 (2010) 141-164.

[10] J.P. Rouse, F. Cortellino, W. Sun, T.H. Hyde, J. Shingledecker, Small punch creep testing: review on modelling and data interpretation, Mater. Sci. Technol. 29 (2013) 13281345 .

[11] R.C. Hurst, K. Matocha, A Renaissance in the Use of the Small Punch Testing Technique, In ASME Pressure Vessels and Piping Conference, (2015) PVP2015-45095. [12] CEN Workshop Agreement. CWA 15627:2006 E, "Small punch test method for metallic materials," CEN, European Committee for Standardization, Brussels Belgium, 2006.

[13] M. Bruchhausen, S. Holmström, I. Simonovski, T. Austin, J.M. Lapetite, S. Ripplinger, F. de Haan, Recent developments in small punch testing: Tensile properties and DBTT, Theor. Appl. Fract. Mech. 86A (2016) 2-10.

[14] P. Dymáček, Recent developments in small punch testing: Applications at elevated temperatures, Theor. Appl. Fract. Mech. 86A (2016) 25-33.

[15] J.H. Bulloch, The small punch toughness test: some detailed fractographic information, Int. J. Pressure Vessels Piping 63 (1995) 177-194. 
[16] C.A. León, R.A.L. Drew, Small punch testing for assessing the tensile strength of gradient Al/Ni-SiC composites, Mater. Lett. 56 (2002) 812-816.

[17] V.L. Giddings, S.M. Kurtz, C.W. Jewett, J.R. Foulds, A.A. Edidin, A small punch test technique for characterizing the elastic modulus and fracture behavior of PMMA bone cement used in total joint replacement, Biomaterials 22 (2001) 1875-1881.

[18] M. Evans, D. Wang, The small punch creep test: some results from a numerical model, J. Mater. Sci. 43 (2008) 1825-1835.

[19] Z. Yang, Z. Wang, Relationship between strain and central deflection in small punch creep specimens, Int. J. Pressure Vessels Piping 80 (2003) 397-404.

[20] J.H. Bulloch, A study concerning material fracture toughness and some small punch test data for low alloy steels, Eng. Failure Anal. 11 (2004) 635-653.

[21] C. Rodríguez, E. Cárdenas, F.J. Belzunce, C. Betegón, Fracture Characterization of Steels by Means of the Small Punch Test, Exp. Mech. 53 (2013) 385-392.

[22] Y. Li, R. Sturm, Determination of Creep Properties From Small Punch Test, Proc. ASME Pressure Vessels \& Piping Division Conference, Chicago, USA, (2008) 739-750.

[23] C. Wen, T. Xu, K. Guan, Correlation Factor Study of Small Punch Creep Test and Its Life Prediction, Materials 9 (2016) 796.

[24] T.E. García, C. Rodríguez, F.J. Belzunce, C. Suárez, Estimation of the mechanical properties of metallic materials by means of the small punch test, J. Alloys Compd. 582 (2014) 708-717.

[25] T.H. Hyde, W. Sun, Some considerations on specimen types for small sample creep tests, Mater. High Temp. 27 (2010) 157-165.

[26] H. Chen, G.A. Jackson, W. Sun, An Overview of Using Small Punch Testing for Mechanical Characterization of MCrAlY Bond Coats, J. Therm. Spray Technol. 26 (2017) 1222-1238.

[27] M.P. Taylor, H.E. Evans, E.P. Busso, Z.Q. Qian, Creep properties of a Pt-aluminide coating, Acta Mater. 54 (2006) 3241-3252.

[28] J. Kameda, T.E. Bloomer, Y. Sugita, A. Ito, S. Sakurai, Mechanical properties of aluminized CoCrAlY coatings in advanced gas turbine blades, Mater. Sci. Eng. A 234-236 (1997) 489-492.

[29] J. Kameda, T.E. Bloomer, Y. Sugita, A. Ito, S. Sakurai, High temperature environmental attack and mechanical degradation of coatings in gas turbine blades, Mater. Sci. Eng. A 229 (1997) 42-54.

[30] J. Kameda, T. Bloomer, S. Sakurai, Oxidation/carbonization/nitridation and in-service mechanical property degradation of CoCrAlY coatings in land-based gas turbine blades, J. Therm. Spray Technol. 8 (1999) 440-446.

[31] M. Eskner, R. Sandström, Measurement of the ductile-to-brittle transition temperature in a nickel aluminide coating by a miniaturised disc bending test technique, Surf. Coat. Technol. 165 (2003) 71-80.

[32] M. Eskner, R. Sandström, Mechanical properties and temperature dependence of an air plasma-sprayed NiCoCrAlY bondcoat, Surf. Coat. Technol. 200 (2006) 2695-2703.

[33] S. Soltysiak, M. Selent, S. Roth, M. Abendroth, M. Hoffmann, H. Biermann, M. Kuna, High-temperature small punch test for mechanical characterization of a nickel-base super alloy, Mater. Sci. Eng. A 613 (2014) 259-263.

[34] H. Chen, T.H. Hyde, K.T. Voisey, D.G. McCartney, Application of small punch creep testing to a thermally sprayed CoNiCrAlY bond coat, Mater. Sci. Eng. A 585 (2013) 205-213. [35] H. Chen, T.H. Hyde, Use of multi-step loading small punch test to investigate the ductile-to-brittle transition behaviour of a thermally sprayed CoNiCrAlY coating, Mater. Sci. Eng. A 680 (2017) 203-209.

[36] G.A. Jackson, H. Chen, W. Sun, D.G. Mccartney, The high temperature creep properties of a thermally sprayed CoNiCrAlY coating via small punch creep testing, Key Eng. Mater. 734 (2017) 37-48. 
[37] S. Saeidi, K.T. Voisey, D.G. McCartney, The Effect of Heat Treatment on the Oxidation Behavior of HVOF and VPS CoNiCrAlY Coatings, J. Therm. Spray Technol. 18 (2009) 209216.

[38] S. Saeidi, K.T. Voisey, D.G. McCartney, Mechanical Properties and Microstructure of VPS and HVOF CoNiCrAlY Coatings, J. Therm. Spray Technol. 20 (2011) 1231-1243.

[39] H. Chen, G.A. Jackson, K.T. Voisey, D.G. McCartney, Modelling and experimental study on $\beta$-phase depletion behaviour of HVOF sprayed free-standing CoNiCrAlY coatings during oxidation, Surf. Coat. Technol. 291 (2016) 34-42.

[40] H. Chen, Microstructure characterisation of un-melted particles in a plasma sprayed CoNiCrAlY coating, Mater. Charact. 136 (2018) 444-451.

[41] H. Chen, Y.Q. Si, D.G. McCartney, An analytical approach to the $\beta$-phase coarsening behaviour in a thermally sprayed CoNiCrAlY bond coat alloy, J. Alloys Compd. 704 (2017) 359-365.

[42] H. Chen, D.G. McCartney, Some aspects on modelling of the $\beta$-phase depletion behaviour under different oxide growth kinetics in HVOF CoNiCrAlY coatings, Surf. Coat. Technol. 313 (2017) 107-114.

[43] P. Richer, M. Yandouzi, L. Beauvais, B. Jodoin, Oxidation behaviour of CoNiCrAlY bond coats produced by plasma, HVOF and cold gas dynamic spraying, Surf. Coat. Technol. 204 (2010) 3962-3974.

[44] G.A. Jackson, W. Sun, D.G. Mccartney, The Application of the Small Punch Tensile Test to Evaluate the Ductile to Brittle Transition of a Thermally Sprayed CoNiCrAlY Coating, Key Eng. Mater. 734 (2017) 144-155.

[45] S. Sampath, H. Herman, Rapid solidification and microstructure development during plasma spray deposition, J. Therm. Spray Technol. 5 (1996) 445-456.

[46] B.J. Kim, Y.B. Sim, J.H. Lee, M.K. Kim, B.S. Lim, Application of small punch creep test for Inconel 617 alloy weldment, Procedia Engineering 10 (2011) 2579-2584.

[47] R.D. Noebe, R.R. Bowman, M.V. Nathal, Physical and mechanical properties of the B2 compound NiAl, Int. Mater. Rev. 38 (1993) 193-232.

[48] H. Chen, Application of Precipitate Free Zone Growth Kinetics to the $\beta$-Phase Depletion Behavior in a CoNiCrAlY Coating Alloy: An Analytical Approach, Metall. Mater. Trans. A 49 (2018) 2551-2560. 